\title{
JÓVENES UNIVERSITARIOS FRENTE AL CAMBIO CLIMÁTICO: PERCEPCIONES, REPRESENTACIONES YACCIONES
}

\section{YOUTH UNIVERSITY FACING CLIMATE CHANGE: PERCEPTIONS, REPRESENTATIONS AND ACTIONS}

\author{
Henry Orlando Luna Pereira ${ }^{1}$ \\ Gerson Rueda Vera ${ }^{2}$ \\ William Rodrigo Avendaño Castro ${ }^{3}$
}

Colombia

1 Doctor en Ciencias Administrativas UNESR (Caracas, Venezuela). Docente - Investigador de la Universidad Francisco de Paula Santander (Cúcuta, Colombia). Correo: henryorlandolp@ufps.edu.co Orcid: https://orcid.org/0000-0003-2741-9170 https://scholar. google.es/citations? user=c6C8JKIAAAAJ\&hl=es Research Gate: $\quad$ https://www.researchgate.net/profile/Henry-Luna CvLac: https://scienti.minciencias.gov.co/cvlac/visualizador/ generarCurriculoCv.do?cod $r h=0000606928$

2 Doctor (c) Educación de la Universidad Pedagógica Experimental Libertador UPEL (Rubio, Venezuela). Docente - Investigador de la Universidad Francisco de Paula Santander (Cúcuta, Colombia). Correo: gersonruedavera@ufps.edu.co Orcid https://orcid.org/00000001-9032-7100 Google Scholar: https://scholar.google. es/citations? user=ifqQGaoAAAAJ\&hl=es Research Gate: https://www.researchgate.net/profile/Gerson-Rueda-Vera Cvlac: https://scienti.minciencias.gov.co/cvlac/visualizador/ generarCurriculoCv.do?cod $r h=0001342587$

3 Doctor en Ciencias Sociales y Humanas de la Pontificia Universidad Javeriana (Bogotá, Colombia). Docente - Investigador de la Universidad Francisco de Paula Santander (Cúcuta, Colombia). Correo: williamavendano@ ufps.edu.co Orcid: http://orcid.org/0000-00027510-8222 Google Scholar: https://scholar.google.es/ citations? user=bRoSgxgAAAAJ\&hl=es Research Gate: https://www.researchgate.net/profile/William-AvendanoCastro CvLac: https://scienti.minciencias.gov.co/cvlac/ visualizador/generarCurriculoCv.do?cod_rh=0001136127

\section{RESUMEN}

Se describen las percepciones, representaciones y acciones de jóvenes universitarios frente al cambio climático. Corresponde a una investigación cuantitativa no experimental de nivel descriptiva y enmarcada en el paradigma empírico-analítico. Participaron en el estudio 541 jóvenes de pregrado de una universidad pública de la ciudad de Cúcuta. Se diseñó un cuestionario que integró tres variables: aspectos sociodemográficos, percepciones y representaciones, y acciones frente al cambio climático. El instrumento fue validado a través de juicio de expertos y una prueba piloto. Los resultados del estudio muestran que los jóvenes universitarios tienen ideas, imágenes y conceptos fragmentados en torno al cambio climático, los cuales influyen en las escasas 
acciones y estrategias que se diseñan para aprontar el fenómeno en mención.

\section{PALABRAS CLAVE:}

Cambio climático, Estudiantes universitarios, Percepciones, Representaciones sociales.

\section{ABSTRACT}

Describe the perceptions, representations and actions of university students regarding climate change. It corresponds to a nonexperimental quantitative research of descriptive level and framed in the empirical-analytical paradigm. A total of 541 undergraduate students from a public university in the city of Cúcuta participated in the study. A questionnaire was designed that integrated three variables: sociodemographic aspects, perceptions and representations, and actions against climate change. The instrument was validated through expert judgment and a pilot test. The results of the study show that young university students have fragmented ideas, images and concepts regarding climate change, which influence the few actions and strategies that are designed to address the phenomenon in question.

\section{KEYWORDS:}

Climate change, University students, Perceptions, Social representations.

\section{INTRODUCCIÓN}

El territorio colombiano no es ajeno al cambio climático. Aún más, ningún país o espacio geográfico se encuentra exento de los efectos de este fenómeno, y eso se debe a que el clima hace parte integral del sistema planeta tierra, atravesando los múltiples sistemas tanto naturales como sociales que hacen parte de este gran sistema (Pickel 2016; Forero Saldarriaga y Vargas 2017). Incluso, se habla del sistema climático, el cual se encuentra integrado por "ochos esferas, cinco naturales y tres antrópicas que interaccionan entre sí; las primeras son la atmósfera, la biosfera, la hidrosfera, la geosfera y la criosfera; las segundas, la economía, la sociedad y la cultura" (Sánchez et al. 2015, 72). Por todo ello, se entiende el cambio climático como un problema de alcance global que afecta todas las poblaciones humanas (Nawrotzki et al. 2015).

Se debe interpretar y analizar el cambio climático desde una perspectiva sistémica en el que múltiples relaciones y conexiones se tejen entre varios sistemas naturales y antrópicos (o sociales). La acción del ser humano enmarcada en una cultura, un orden social y un sistema económico de corte neoliberal, produce y consume de forma salvaje y desmedida (Ambrogi 2016), agota los recursos naturales, arrasa con los ecosistemas y genera variados gases como el dióxido de carbono, el metano, los óxidos nitrosos, entre otros (Ballesteros y León 2016).

Todo ello afecta el sistema climático natural de la tierra, modificando las temperaturas globales y provocando variedad de fenómenos -algunos más graduales que otros- como el derretimiento de grandes capas de hielo, aumento del nivel del mar, olas de calor, sequías, incendios, deslizamientos, inundaciones, muertes de especies, cambios en los suelos, y otros (Nawrotzki et al. 2015; Riosmena Nawrotzki y Hunter 2018; Forero Saldarriaga y Vargas 2017). Las consecuencias de todo ello, alcanza al ser humano y a los sistemas antrópicos en forma de sucesos y eventos complejos como migraciones y desplazamientos ambientales, hambre, enfermedades, agotamiento de recursos, escases del agua, baja calidad del aire, daños en la infraestructura y los asentamientos, etcétera (Avendaño y Aguilar 2014; Departamento Nacional de Planeación -DNP- 2018). Para Nawrotzki et al. (2015), el cambio climático tiene mayores posibilidades 
impactar los países menos desarrollados dada su inadecuada infraestructura y capital financiero limitado para la inversión en medidas de protección (tecnológicas y diques).

La evidencia sobre el impacto o los efectos del cambio climático en el contexto colombiano es variada, aunque son escasos los estudios y las investigaciones en este tema particular (Forero Saldarriaga y Vargas 2017). Se ha corroborado la reducción de la cubierta de hielo en los nevados y glaciares del país, por ejemplo, entre el 2002 y 2003 se redujo el área glaciar en $55,44 \mathrm{~km}^{2}$ y en el periodo del 2006 y 2007 , la reducción fue de $47,1 \mathrm{~km}^{2}$ (Departamento Nacional de Planeación -DNP- 2018). Se estima que, en los últimos 50 años, las temperaturas del país han aumentado en $0.65^{\circ}$ centígrados (Forero Saldarriaga y Vargas 2017).

También hay evidencia de que el nivel del mar en la Costa Caribe ha aumentado en $3,5 \mathrm{~mm}$ por año, y similar información se presenta en la Costa del Pacífico. Los Parques Naturales del territorio, así como michos bosques y cuencas, han sido afectados por fenómenos de naturales como el de 'La Niña' que tuvo lugar entre el 2010 y 2011 (Departamento Nacional de Planeación -DNP- 2018). Este fenómeno también generó la migración ambiental de la mayoría de los pobladores del municipio de Gramalote en el departamento Norte de Santander entre diciembre de 2010 y enero de 2011 (Avendaño Patiño y Aguilar 2017).

El cambio climático ha tenido efectos sobre el sector agropecuario. Con el fenómeno de 'El Niño', se afectó la producción agrícola por las sequias y heladas generadas en el periodo 2007. Igualmente, se presentaron inundaciones sobre el $3 \%$ de la superficie ganadera como resultado de 'La Niña' entre el 2010 y 2011. También los cultivos se vieron seriamente afectados, lo que provocó millonarias pérdidas económicas para la población rural. En el campo de la salud, se ha observado el aumento de infecciones respiratorias y el crecimiento alarmante de casos de malaria, cólera, tuberculosis y dengue. Los daños en infraestructura de carreteras, vías y viviendas como consecuencia del fenómeno de 'La Niña', se suma a los variados efectos del cambio climático (Departamento Nacional de Planeación -DNP- 2018).

El problema complejo que envuelve el cambio climático, exige medidas de todo tipo en distintos niveles. Estas incluyen políticas públicas, leyes y reglamentaciones generales y específicas, por ejemplo, el Plan Nacional de Adaptación al Cambio Climático (DNP 2018), la Política Nacional de Cambio Climático (Ministerio de Ambiente y Desarrollo Sostenible 2017), la Ley 1931 de 2018 que establece directrices para la gestión del cambio climático (Congreso de la República 2018, 27 de julio) y el reciente Proyecto de Ley 208/2019 Cámara que se debate en el Congreso, y que busca fijar parámetros para el fomento de la construcción sostenible en Colombia (Congreso de la República 2019).

Pero también se requieren medidas regionales, locales y microsociales que se ajusten a los recursos existentes y requeridos, las condiciones ecosistémicas y de biodiversidad, las prácticas económicas y socioculturales, y al capital financiero disponible. En este sentido, las prácticas y acciones de los individuos, resultan fundamentales para generar pequeños cambios positivos que hagan frente al cambio climático. Sin embargo, estas dependen de las percepciones, las representaciones y los significados colectivamente construidos (Wibeck 2014; Moloney et al. 2014; Ulloa 2011, Parra Castillo y Vallejos 2013; Flores y Terrón 2018; Flores 2019), aún más en una era de medios de comunicación e información donde el tema 'cambio climático' es discutido por radio, televisión, páginas de internet y redes sociales.

A partir de las representaciones sociales y percepciones es que los sujetos toman 
decisiones y cursos de acción en diferentes niveles y escenarios (Flores y Terrón 2018).

Considerando todo lo anterior, se ha adelantado un estudio en el contexto de la ciudad de Cúcuta en Norte de Santander (Colombia) con el objetivo de identificar las percepciones, representaciones y acciones de jóvenes universitarios frente al cambio climático. En este territorio, la variabilidad del clima ha generado olas de calor significativas que producen reducciones en las fuentes hídricas de la ciudad, sequías e incendios forestales que se extienden a todo el departamento, así como temporadas frías que conllevan a inundaciones y deslizamientos que, sumados a la inadecuada infraestructura e ineficiente planeación del territorio, aumentan los riesgos para las comunidades. De seguir avanzando el cambio climático, en pocos años la ciudad, su área metropolitana -integrada junto a los municipios de Villa del Rosario y Los Patios-, y otros municipios del departamento, estarán enfrentando variados fenómenos naturales con probabilidades de alto impacto sobre la población y sus recursos, incluidas migraciones ambientales como fue el caso del municipio de Gramalote en el 2010-2011 (Avendaño 2018).

\section{PERCEPCIONES Y REPRESENTACIONES SOCIALES EN TORNO AL CAMBIO CLIMÁTICO: REVISIÓN DE LA LITERATURA}

Las representaciones sociales se
encuentran asociadas al conocimiento
construido por los individuos: el ser humano conoce sobre los objetos que percibe en diferentes niveles de abstracción, y sobre ellos, construye representaciones mentales como si se tratara de imágenes que varían y no son exactas a la realidad (Jodolet 1986). Estas representaciones, la mayoría de veces, no llegan de manera puras al sujeto que conoce, sino que vienen siendo el resultado de actos sociales mediados, por ejemplo, la familia, la escuela, los grupos sociales, las redes, los medios de comunicación, entre otros; y que brindan sentido y valor colectivo.

De esta manera, se habla de representaciones sociales en la medida que los objetos aprehendidos cognoscitivamente por el sujeto son el resultado de interacciones sociales que ya han modificado el objeto de conocimiento: "este conocimiento representacional y de carácter social dice que forjamos representaciones de aquello que vemos, representaciones que están influidas por la sociedad donde vivimos con el fin de dar sentido a lo que vemos, de orientarnos con respecto a ello" (García Rosas y Leco 2010, 61).

La teoría de las representaciones sociales surge con los aportes de Moscovici $(1979,27)$ en la década de los setenta. Para este psicólogo rumano, "las representaciones sociales son entidades casi tangibles [que] circulan, se cruzan y se cristalizan en nuestro universo cotidiano a través de una palabra, un gesto, un encuentro". Dicho de otra manera, las representaciones se hacen presentes en toda actividad humana, especialmente, en el ámbito de la comunicación. Para Domínguez (2001), las representaciones sociales corresponden a imágenes que integran significados y sistemas de referencia que le permiten al individuo interpretar la realidad, dar sentido al mundo y clasificar / categorizar fenómenos, circunstancias e incluso, otras personas.

Las representaciones sociales se relacionan con el sentido común (Moscovici 1998; Flores y Terrón 2018). El sentido común es el espacio consensuado y en el que se reconoce el carácter histórico, cultural y retórico de los sujetos como grupo social. Por ello, el sentido común permite acceder a las representaciones sociales en vivo, facilitando que estas constituyan un fenómeno observable (Moscovici 1998). Al analizar las representaciones sociales desde el sentido común, se habilitan rutas metodológicas para el estudio de las 
mismas, pues se convierten en hechos sociales observables para el investigador sobre las cuales se pueden hallar sentidos y estructuras. Igualmente, se supera la idea del sentido común como pensamiento irracional y desestructurado, ubicando las representaciones sociales en el amplio abanico que hace parte del pensamiento social (Domínguez 2001).

De acuerdo a Flores y Terrón (2018), las representaciones sociales integran tres dimensiones: "la información, el campo de representación y la actitudinal" (220). Así mismo, expresa que la teoría las representaciones sociales "centra su atención en el conocimiento de sentido común, referido a grandes parcelas de la realidad, como el mundo físico, el mundo de la vida o el mundo social, o aspectos muy limitados como una práctica profesional específica" (221), y un ejemplo de porción realidad lo constituye el cambio climático. Entonces, un individuo forma representaciones sociales sobre todas realidades a las que es expuesto, pero dicha representación depende de la información que posea el sujeto, el campo de representación en la que se encuentra dicha información y en la actitud asumida. En resumen, se debe tener en cuenta que la teoría de las representaciones sociales:

[...] tiene gran vigencia ya que abrió un espacio de investigación esencial para comprender los fenómenos sociopolíticos $y$ ambientales de interés actual: el estudio del "conocimiento del sentido común". Acceder a las representaciones sociales a partir de procesos comunicativos nos permite comprender cómo piensan los individuos y cómo organizan su vida cotidiana en las esferas de lo privado y lo público. (Santiago Horita y Sulvavarán 2018, 2)
De manera general, se puede entender el cambio climático como un fenómeno producido por el aumento de gases de efecto de invernadero -dióxido de carbono, metano y dióxido de nitrógeno-, los cuales atrapan el calor. Dicho crecimiento tiene su origen en la actividad humana asociada a la quema de combustibles fósiles, al cambio en el uso de la tierra, la deforestación, la contaminación oceánica, y otro tipo de prácticas (Ambrogi 2016; Kellogg 2019; Kellogg y Schware 2018; Naciones Unidas 2007). A su vez, los gases de efecto invernadero generan un aumento del calor retenido en la atmósfera de la tierra -calentamiento global-, produciendo un aumento gradual de la temperatura global, cambios en las nubes, aumento de las precipitaciones, derretimiento de glaciares y capas de hielo, acrecimiento de la acidez de los océanos, subida de los niveles de las aguas, entre otros (Harvey 2000; Naciones Unidas 2007).

En consecuencia, la superficie de la tierra se ve expuesta a un calentamiento que altera la transferencia natural de energía entre atmósfera, espacio, tierra y océanos, produciéndose un cambio global del clima y un aumento de los desastres como tormentas, deslizamientos, sequías, pérdida agrícola y de especies, degradación de la tierra, y epidemias. En las últimas cuatro décadas, la temperatura del planeta tierra ha aumentado $1.4^{\circ} \mathrm{F}$, los niveles de gases de dióxido de carbono han llegado a 400.71 partes por mil millones, se han perdido $1.500 .000 \mathrm{~km}^{2}$ de cubierta forestal, se han reducido 287 mil millones toneladas métricas por año de hielo y el nivel del mar ha aumentado $3.2 \mathrm{~mm}$ por año (Sivaramanan 2016).

Los estudios relacionados con las representaciones sociales sobre el cambio climático, son variados dentro de la literatura. En parte, esto se debe a la importancia y emergencia que envuelve el fenómeno del cambio climático como problema estructural y global de nuestro 
tiempo. La investigación de Flores y Terrón (2018) se analizan los principales componentes o dimensiones de las representaciones sociales frente al cambio climático en estudiantes de la Universidad Pedagógica Nacional en México, haciendo especial énfasis en las emociones. Los resultados mostraron que las emociones "constituyen un componente relevante en las representaciones sociales y pueden ser investigadas desde el campo de la educación ambiental" (217).

También Flores (2019) adelantó un estudio con estudiantes de dos universidades mexicanas con el objetivo de "identificar las representaciones sociales que poseen sobre el cambio climático" (7). A diferencia del primer estudio (Flores y Terrón 2018), donde utilizó un enfoque cualitativo apoyado en la entrevista y el análisis de discurso, en éste hubo un enfoque mixto en el que se implementaron entrevistas, encuestas semiestructuradas, cuestionarios con escala tipo Likert y una carta asociativa. Los resultados mostraron representaciones sociales similares para estudiantes hombres y mujeres, pero actitudes más favorables en el sexo femenino. Así mismo, indica que "en las representaciones predominan la información sobre los efectos del cambio climático y el reconocimiento de la importancia de la educación ambiental" (22).

El estudio de Santiago, Horita y Sulvavarán (2018) también se contextualiza en México, pero con comunidades rurales del Estado de Chiapas, y en donde se indaga por las representaciones sociales de hombres y mujeres en torno a los cambios ambientales ocurridos. Bajo un paradigma interpretativo, un enfoque cualitativo y un diseño hermenéutico, se entrevistaron a sabios de estas comunidades. Los hallazgos muestran "un fuerte consenso sobre la percepción de un aumento en la temperatura y cambios en el patrón de lluvias, lo cual concuerda con los escenarios modelados para el estado, desde la visión de la ciencia occidental" (1).

En Cuba, se encuentra el estudio de Miranda et al. (2019), el cual buscó identificar las percepciones sociales que tienen las comunidades costeras de la provincia de Cienfuegos en torno a los fenómenos del cambio climático. A partir de una metodología con enfoque mixto (diseños: estudio de caso y no experimental -análisis estadístico descriptivo), se logró identificar representaciones sociales específicas y particulares de las comunidades costeras sobre el cambio climático, y que guían la acción y participación de la sociedad en la construcción de instituciones y estrategias de adaptación al fenómeno:

Las comunidades ofrecen criterios
que en el orden metodológico
constituyen herramientas de
trabajo a los decisores para la toma
de decisiones respecto a medidas
de adaptación y mitigación
relacionadas con el efecto de
fenómenos meteorológicos
intensos y ofrecen las vías por
las que se puede canalizar la
participación pública en esas
medidas. (Miranda et al. 2019,
352),

La investigación de Teso (2017) en España, enlaza comunicación, representaciones sociales y cambio climático desde el campo de la sociología. En este estudio, se buscó analizar la representación del cambio climático en la televisión a partir de su discurso, las representaciones sociales construidas por los jóvenes españoles respecto del mismo tema y el discurso de los expertos en este tema; a fin de identificar elementos comunes y ausentes, diferencias y errores presentes. Los hallazgos del estudio muestran que el discurso televisivo está centrado, particularmente, en los 
impactos y las soluciones al cambio climático, pero en menor medida a las causas de este fenómeno. De igual forma, las representaciones sociales de los jóvenes giran, principalmente, en los impactos del cambio climático según imágenes descritas por los participantes y las representaciones asociadas a las causas son mayores que las del discurso televisivo, pero en términos de soluciones, las representaciones son escasas: "la mitad de los encuestados desconoce el Protocolo de Kioto y considera que las soluciones son antes globales que locales" (IV).

El estudio de García et al. (2019) permite complementar los hallazgos del estudio de Teso (2017). En efecto, estos investigadores realizaron un estudio con 644 estudiantes de la Universidad de Santiago de Compostela en España, en donde se aplicó un cuestionario cerrado para reconocer la alfabetización climática de dos grupos de participantes. Los resultados comparados entre sujetos de primer y cuarto año, sugieren que la información con la que los estudiantes construyen las representaciones en torno al cambio climático, no provienen de su formación académica universitaria, sino de la etapa secundaria y las experiencias fuera del sistema educativo.

Por último, resulta preciso hacer mención de la investigación de Batel et al. (2016), la cual sugiere la necesidad de complementar la teoría de las representaciones sociales con la teoría de las prácticas sociales tratándose de temas medio ambientales como el cambio climático y la necesidad de forjar cambios sociales. De acuerdo a estos autores, las perspectivas sociopsicológicas y sociológicas convencionales inmersas en la teoría de las representaciones sociales, tienden a suponer que el cambio individual equivale al cambio social o excluyen otras perspectivas de la psicología social. En ese sentido, se pueden articular ambas teorías con el objetivo de comprender las diferentes etapas del proceso de cambio social hacia sociedades más sostenibles para el medio ambiente.

\section{MÉTODO}

Corresponde a un estudio cuantitativo no experimental de nivel descriptivo y correlacional enmarcado en el paradigma empírico analítico. Participaron dentro del estudio, 4.500 estudiantes de pregrado de la Facultad de Ciencias Empresariales de una universidad pública de la ciudad de Cúcuta. La Facultad fue seleccionada por los compromisos inherentes que tienen los futuros profesionales frente a temas medio ambientales como el cambio climático. La población estuvo integrada por 541 estudiantes distribuidos entre las carreras administración de empresas, comercio internacional y contaduría pública. Se utilizó un muestreo aleatorio simple y se calculó la muestra a través de una fórmula estadística para el $98 \%$ de confiabilidad y $5 \%$ de margen de error.

Se utilizó como instrumento, un cuestionario con aspectos sociodemográficos y 23 vinculadas a las variables: percepciones y representaciones del cambio climático, y acciones de los jóvenes frente al cambio climático. En la tabla 1 se hace la descripción de las dimensiones para cada una de estas variables. 
Tabla 1. Variables y dimensiones de estudio

\begin{tabular}{|c|c|c|}
\hline $\begin{array}{l}\text { Variables del } \\
\text { estudio }\end{array}$ & Dimensiones & $\begin{array}{l}\text { Ítems del } \\
\text { cuestionario }\end{array}$ \\
\hline \multirow{6}{*}{$\begin{array}{l}\text { Datos } \\
\text { sociodemográfico }\end{array}$} & Edad & \multirow[t]{6}{*}{$1-6$} \\
\hline & Sexo & \\
\hline & Estrato socio-económico & \\
\hline & Semestre que cursa & \\
\hline & Domicilio & \\
\hline & Condición especial & \\
\hline \multirow{16}{*}{$\begin{array}{l}\text { Percepciones y } \\
\text { representaciones }\end{array}$} & Percepción del conocimiento sobre el cambio climático & \multirow[t]{16}{*}{$7-22$} \\
\hline & Lo que sé sobre el cambio climático & \\
\hline & $\begin{array}{l}\text { Medios por los cuales me informo en torno al cambio } \\
\text { climático }\end{array}$ & \\
\hline & Conceptos asociados al cambio climático & \\
\hline & $\begin{array}{l}\text { Asociación entre el cambio climático y otros problemas } \\
\text { estructurales }\end{array}$ & \\
\hline & $\begin{array}{l}\text { Asociaciones entre el cambio climático y fenómenos } \\
\text { próximos }\end{array}$ & \\
\hline & Importancia individual -propia- del cambio climático & \\
\hline & $\begin{array}{l}\text { Importancia del cambio climático en las organizaciones } \\
\text { gubernamentales }\end{array}$ & \\
\hline & Importancia del cambio climático entre las personas & \\
\hline & Importancia del cambio climático en las Universidades & \\
\hline & $\begin{array}{l}\text { Importancia del cambio climático entre los medios de } \\
\text { comunicación }\end{array}$ & \\
\hline & $\begin{array}{l}\text { Importancia del cambio climático a nivel local - } \\
\text { departamental }\end{array}$ & \\
\hline & Factores asociados al cambio climático & \\
\hline & Responsables del cambio climático & \\
\hline & Efectos del cambio climático & \\
\hline & Impactos del cambio climático sobre el mismo individuo & \\
\hline \multirow[t]{7}{*}{ Acciones } & Actitudes & \multirow[t]{7}{*}{$23-29$} \\
\hline & Consulta y aprehensión de conocimientos & \\
\hline & Consumo de energía & \\
\hline & Uso de fuentes contaminantes & \\
\hline & Consumo de bienes & \\
\hline & Movilización social & \\
\hline & Estrategias y proyectos propios & \\
\hline
\end{tabular}


El instrumento fue sometido a juicio de expertos, y tras el concepto favorable de los doctores que la validaron, se aplicó una prueba piloto para determinar posibles errores y hacer las modificaciones respectivas. La aplicación del instrumento se adelantó de manera virtual considerando la situación excepcional provocada por el Covid-19 en el país. Una vez que se recolectaron todos los datos, estos se descargaron en una tabla de Excel donde fueron sistematizados y sometidos a un análisis de estadística descriptiva.

\section{RESULTADOS}

En la tabla 2 se muestran las características sociodemográficas de los participantes. Las mujeres integraron el $63,6 \%$ de la muestra y los hombres el $36,4 \%$. La mayoría de los jóvenes se encuentran entre los 15 y 25 años de edad $(91.6 \%)$ y en los estratos socioeconómicos 1 y 2 (85,6\%). Respecto de las carreras, los participantes del programa de comercio internacional representan el $39,4 \%$ del total de la muestra, mientras que los participantes que cursan administración de empresas y contaduría pública representan el $32,0 \%$ y $28,7 \%$ del total de la muestra, respectivamente.

Se presentaron estudiantes de todos los semestres de cada una de las carreras. En la mayoría de los casos, el porcentaje de participantes por semestre fue superior al $10 \%$, excepto en los semestres $7^{\circ}, 8^{\circ}, 9^{\circ}$ y $10^{\circ}$. Respecto del domicilio, la mayoría de participantes tienen residencia en el sector urbano $(95,2 \%)$ y sólo un $14,8 \%$ de los estudiantes tienen alguna condición especial: víctima del conflicto armado interno (10,4\%), afrodescendiente $(2,4 \%)$, situación de discapacidad $(1,3 \%)$ e indígena $(0,7 \%)$. Valga señalar que, en esta pregunta, algunos estudiantes agregaron situaciones que en su concepto resultan condiciones especiales, por ejemplo, 'sin acceso a internet', 'pobreza extrema', 'desempleo', 'madre desplazada' y 'madre cabeza de hogar'. 
Tabla 2. Características sociodemográficas de los participantes

\begin{tabular}{|c|c|c|c|}
\hline Dimensión & Ítem & No & Porcentaje \\
\hline \multirow[t]{2}{*}{ Sexo } & Hombre & 197 & $36,4 \%$ \\
\hline & Mujer & 344 & $63,6 \%$ \\
\hline \multirow[t]{4}{*}{ Edad } & 15-20 años & 296 & $54,7 \%$ \\
\hline & 21-25 años & 194 & $35,9 \%$ \\
\hline & 26-30 años & 38 & $7,0 \%$ \\
\hline & Más de 30 años & 13 & $2,4 \%$ \\
\hline \multirow[t]{6}{*}{ Estrato socioeconómico } & Uno & 182 & $32,6 \%$ \\
\hline & Dos & 287 & $53,0 \%$ \\
\hline & Tres & 65 & $12,0 \%$ \\
\hline & Cuatro & 6 & $1,1 \%$ \\
\hline & Cinco & 5 & $1,02 \%$ \\
\hline & Seis & 0 & 0 \\
\hline \multirow[t]{3}{*}{ Programa académico } & Administración de empresas & 173 & $32,0 \%$ \\
\hline & Comercio internacional & 213 & $39,4 \%$ \\
\hline & Contaduría pública & 155 & $28,7 \%$ \\
\hline \multirow{10}{*}{ Semestre que cursa } & Primero & 48 & $8,9 \%$ \\
\hline & Segundo & 55 & $10,2 \%$ \\
\hline & Tercero & 82 & $15,2 \%$ \\
\hline & Cuarto & 95 & $17,6 \%$ \\
\hline & Quinto & 64 & $11,8 \%$ \\
\hline & Sexto & 54 & $10,0 \%$ \\
\hline & Séptimo & 40 & $7,4 \%$ \\
\hline & Octavo & 48 & $8,9 \%$ \\
\hline & Noveno & 14 & $2,6 \%$ \\
\hline & Décimo & 41 & $7,6 \%$ \\
\hline \multirow[t]{2}{*}{ Domicilio } & Urbano & 515 & $95,2 \%$ \\
\hline & Rural & 26 & $4,8 \%$ \\
\hline \multirow[t]{6}{*}{ Condición especial } & Víctima del conflicto armado & 56 & $10,4 \%$ \\
\hline & Afrodescendiente & 13 & $2,4 \%$ \\
\hline & Indígena & 4 & $0,7 \%$ \\
\hline & Situación de discapacidad & 7 & $1,3 \%$ \\
\hline & Otro & 0 & 0 \\
\hline & Ninguno & 461 & $85.2 \%$ \\
\hline
\end{tabular}

Fuente: elaboración propia 
En la tabla 3 se presentan los resultados obtenidos en la variable precepciones y representaciones del cambio climático. En general, el $80 \%$ de los participantes consideran que conocen algo sobre el tema del cambio climático. Tan sólo un 12,4\% expresa que conoce bastante sobre el tema y un $7,6 \%$ considera que no sabe muy bien o no sabe nada sobre el tema. El 100\% de los estudiantes ha escuchado hablar sobre el fenómeno del cambio climático.

Tabla 3. Resultados del cuestionario en torno a la variable percepciones y representaciones del cambio climático

\begin{tabular}{|c|c|c|c|c|}
\hline Dimensión & Ítem & Opciones & No & $\%$ \\
\hline \multirow{5}{*}{$\begin{array}{l}\text { Percepción del } \\
\text { conocimiento } \\
\text { sobre el cambio } \\
\text { climático }\end{array}$} & \multirow[t]{5}{*}{$\begin{array}{l}\text { 1. ¿Sabe usted que es el } \\
\text { cambio climático? }\end{array}$} & $\begin{array}{l}\text { Si, conozco bastante sobre el } \\
\text { tema }\end{array}$ & 67 & $12,4 \%$ \\
\hline & & $\mathrm{Si}$, conozco algo sobre el tema & 433 & $80,0 \%$ \\
\hline & & No sé bien de que se trata & 39 & $7,2 \%$ \\
\hline & & No sé nada sobre el tema & 2 & $0,4 \%$ \\
\hline & & $\begin{array}{l}\text { Nunca había escuchado el término } \\
\text { cambio climático }\end{array}$ & 0 & 0 \\
\hline \multirow{6}{*}{$\begin{array}{l}\text { Lo que saben } \\
\text { sobre el cambio } \\
\text { climático }\end{array}$} & \multirow[t]{6}{*}{$\begin{array}{l}\text { 2.Desde su percepción, } \\
\text { el cambio climático es: }\end{array}$} & $\begin{array}{l}\text { Un fenómeno global caracterizado } \\
\text { por la variación del clima }\end{array}$ & 341 & $63.0 \%$ \\
\hline & & $\begin{array}{l}\text { Un fenómeno global caracterizado } \\
\text { por el aumento de la temperatura }\end{array}$ & 65 & $12,0 \%$ \\
\hline & & $\begin{array}{l}\text { Un fenómeno global caracterizado } \\
\text { por el deterioro de la capa de } \\
\text { ozono }\end{array}$ & 127 & $23,5 \%$ \\
\hline & & Un fenómeno no global & 2 & $0,4 \%$ \\
\hline & & Un fenómeno que no existe & 1 & $0,2 \%$ \\
\hline & & Otro & 5 & $0,9 \%$ \\
\hline \multirow{6}{*}{$\begin{array}{l}\text { Medios por } \\
\text { los cuales me } \\
\text { informo en } \\
\text { torno al cambio } \\
\text { climático }\end{array}$} & \multirow{6}{*}{$\begin{array}{l}\text { 3. ¿Cuáles son los medios } \\
\text { más comunes donde } \\
\text { encuentras u observas } \\
\text { información sobre el } \\
\text { cambio climático? }\end{array}$} & La televisión y la radio & 242 & $44,7 \%$ \\
\hline & & $\begin{array}{l}\text { Documentales online o en canales } \\
\text { de televisión }\end{array}$ & 242 & $44,7 \%$ \\
\hline & & Foros, blogs y páginas de la Web & 189 & $34,9 \%$ \\
\hline & & Redes sociales & 290 & $53,6 \%$ \\
\hline & & $\begin{array}{l}\text { Documentación académica como } \\
\text { artículos científicos o informes }\end{array}$ & 127 & $23,5 \%$ \\
\hline & & Otro & 2 & $0,4 \%$ \\
\hline
\end{tabular}




\begin{tabular}{|c|c|c|c|c|c|}
\hline \multirow[t]{18}{*}{$\begin{array}{l}\text { Conceptos } \\
\text { asociados al } \\
\text { cambio climático }\end{array}$} & \multirow{18}{*}{$\begin{array}{l}\text { 4.Del siguiente conjunto } \\
\text { de términos, señale los } \\
\text { conceptos que usted } \\
\text { considera tienen relación } \\
\text { directa con el cambio } \\
\text { climático: }\end{array}$} & \multicolumn{2}{|c|}{$\begin{array}{l}\text { Desastres - catástrofes: } \\
\text { inundaciones, sequías tsunamis, } \\
\text { entre otros. }\end{array}$} & 262 & $49,4 \%$ \\
\hline & & \multicolumn{2}{|c|}{ Calentamiento global } & 397 & $73,4 \%$ \\
\hline & & \multicolumn{2}{|c|}{ Efecto invernadero } & 208 & $38,4 \%$ \\
\hline & & \multicolumn{2}{|c|}{ Baja de las temperaturas } & 142 & $26,2 \%$ \\
\hline & & \multicolumn{2}{|c|}{ Contaminación } & 281 & $51,9 \%$ \\
\hline & & \multicolumn{2}{|c|}{ Deforestación } & 198 & $36,6 \%$ \\
\hline & & \multicolumn{2}{|c|}{ Cambio de los suelos } & 61 & $11.3 \%$ \\
\hline & & \multicolumn{2}{|c|}{ Capa de ozono } & 181 & $33,5 \%$ \\
\hline & & \multicolumn{2}{|c|}{ Derretimiento glacial o de los polos } & 196 & $36,2 \%$ \\
\hline & & \multicolumn{2}{|c|}{ Ecosistemas } & 73 & $13,5 \%$ \\
\hline & & \multicolumn{2}{|c|}{ Consumo } & 37 & $6,8 \%$ \\
\hline & & \multicolumn{2}{|c|}{ Productividad } & 23 & $4,3 \%$ \\
\hline & & \multicolumn{2}{|c|}{ Fuentes de energía fósiles } & 50 & $9,2 \%$ \\
\hline & & \multicolumn{2}{|c|}{ Pobreza } & 20 & $3,7 \%$ \\
\hline & & \multicolumn{2}{|c|}{ Hambre } & 12 & $2,2 \%$ \\
\hline & & \multicolumn{2}{|c|}{ Ser humano } & 120 & $22,2 \%$ \\
\hline & & Otro & $\begin{array}{l}\text { Alta demanda de carne de } \\
\text { res }\end{array}$ & 1 & $0,2 \%$ \\
\hline & & & $\begin{array}{l}\text { Todos estos conceptos se } \\
\text { relacionan }\end{array}$ & 1 & $0,2 \%$ \\
\hline \multirow{3}{*}{$\begin{array}{l}\text { Asociación } \\
\text { entre el cambio } \\
\text { climático y otros } \\
\text { problemas } \\
\text { estructurales }\end{array}$} & \multirow{3}{*}{$\begin{array}{l}\text { 5.Desde su perspectiva, } \\
\text { ¿Cree que el cambio } \\
\text { climático se relaciona } \\
\text { con la pobreza, el } \\
\text { hambre, el desempleo y } \\
\text { la calidad de vida? }\end{array}$} & \multicolumn{2}{|c|}{ Si, tienen una relación directa } & 68 & $12,6 \%$ \\
\hline & & \multicolumn{2}{|c|}{$\mathrm{Si}$, tienen una relación indirecta } & 212 & $39,2 \%$ \\
\hline & & \multicolumn{2}{|c|}{$\begin{array}{l}\text { No se puede establecer relaciones } \\
\text { entre el cambio climático y los otros } \\
\text { problemas enunciados }\end{array}$} & 261 & $48,2 \%$ \\
\hline \multirow{2}{*}{$\begin{array}{l}\text { Asociaciones } \\
\text { entre el cambio } \\
\text { climático y } \\
\text { fenómenos } \\
\text { próximos }\end{array}$} & $\begin{array}{l}\text { 6. ¿Ha relacionado el } \\
\text { cambio climático con } \\
\text { alguno }(0 \text { algunos })\end{array}$ & \multicolumn{2}{|c|}{$\begin{array}{l}\mathrm{Si} \text {, algunos problemas del territorio } \\
\text { tienen relación con el cambio } \\
\text { climático }\end{array}$} & 289 & $53,4 \%$ \\
\hline & $\begin{array}{l}\text { problemas de su territorio } \\
\text { (nivel comunitario, local } \\
\text { ¿ departamental)? } \\
\text { ¿Cuáles? }\end{array}$ & \multicolumn{2}{|c|}{$\begin{array}{l}\text { No, no he percibido problemas } \\
\text { del territorio asociados al cambio } \\
\text { climático }\end{array}$} & 252 & $46,6 \%$ \\
\hline \multirow{4}{*}{$\begin{array}{l}\text { Importancia } \\
\text { individual } \\
\text {-propia- del } \\
\text { cambio climático }\end{array}$} & \multirow{4}{*}{$\begin{array}{l}\text { 7.Desde su experiencia } \\
\text { y las actividades } \\
\text { académicas y sociales } \\
\text { desarrolladas, ¿qué } \\
\text { importancia le ha dado al } \\
\text { cambio climático? }\end{array}$} & \multicolumn{2}{|c|}{$\begin{array}{l}\text { Es un tema al que le doy mucha } \\
\text { importancia }\end{array}$} & 208 & $38,4 \%$ \\
\hline & & \multicolumn{2}{|c|}{$\begin{array}{l}\text { Es un tema al que doy algo de } \\
\text { importancia }\end{array}$} & 263 & $48,6 \%$ \\
\hline & & \multicolumn{2}{|c|}{$\begin{array}{l}\text { Es un tema al que le doy poca } \\
\text { importancia }\end{array}$} & 66 & $12,6 \%$ \\
\hline & & \multicolumn{2}{|c|}{$\begin{array}{l}\text { Es un tema al que nunca le he } \\
\text { dado importancia }\end{array}$} & 4 & $0,7 \%$ \\
\hline
\end{tabular}




\begin{tabular}{|c|c|c|c|c|}
\hline \multirow{4}{*}{$\begin{array}{l}\text { Importancia } \\
\text { del cambio } \\
\text { climático en las } \\
\text { organizaciones } \\
\text { gubernamentales }\end{array}$} & \multirow{4}{*}{$\begin{array}{l}\text { 8.Desde su percepción, } \\
\text { ¿qué tanta importancia } \\
\text { le brinda el Estado } \\
\text { y las organizaciones } \\
\text { gubernamentales al tema } \\
\text { del cambio climático? }\end{array}$} & $\begin{array}{l}\text { Es un tema al que le dan mucha } \\
\text { importancia }\end{array}$ & 31 & $5,7 \%$ \\
\hline & & $\begin{array}{l}\text { Es un tema al que dan algo de } \\
\text { importancia }\end{array}$ & 121 & $22,4 \%$ \\
\hline & & $\begin{array}{l}\text { Es un tema al que le dan poca } \\
\text { importancia }\end{array}$ & 321 & $59,3 \%$ \\
\hline & & $\begin{array}{l}\text { Es un tema al que nunca le han } \\
\text { dado importancia }\end{array}$ & 68 & $12,6 \%$ \\
\hline \multirow{4}{*}{$\begin{array}{l}\text { Importancia del } \\
\text { cambio climático } \\
\text { entre las } \\
\text { personas }\end{array}$} & \multirow{4}{*}{$\begin{array}{l}\text { 9. Desde su percepción, } \\
\text { ¿qué tanta importancia } \\
\text { le brindan las personas } \\
\text { o la sociedad al tema del } \\
\text { cambio climático? }\end{array}$} & $\begin{array}{l}\text { Es un tema al que le dan mucha } \\
\text { importancia }\end{array}$ & 20 & $3,7 \%$ \\
\hline & & $\begin{array}{l}\text { Es un tema al que dan algo de } \\
\text { importancia }\end{array}$ & 139 & $25,7 \%$ \\
\hline & & $\begin{array}{l}\text { Es un tema al que le dan poca } \\
\text { importancia }\end{array}$ & 332 & $61,4 \%$ \\
\hline & & $\begin{array}{l}\text { Es un tema al que nunca le han } \\
\text { dado importancia }\end{array}$ & 50 & $9,2 \%$ \\
\hline \multirow{4}{*}{$\begin{array}{l}\text { Importancia } \\
\text { del cambio } \\
\text { climático en las } \\
\text { Universidades }\end{array}$} & \multirow{4}{*}{$\begin{array}{l}\text { 10. Desde su } \\
\text { percepción, ¿qué tanta } \\
\text { importancia le brinda la } \\
\text { Universidad al tema del } \\
\text { cambio climático? }\end{array}$} & $\begin{array}{l}\text { Es un tema al que le dan mucha } \\
\text { importancia }\end{array}$ & 63 & $11,6 \%$ \\
\hline & & $\begin{array}{l}\text { Es un tema al que dan algo de } \\
\text { importancia }\end{array}$ & 259 & $47,9 \%$ \\
\hline & & $\begin{array}{l}\text { Es un tema al que le dan poca } \\
\text { importancia }\end{array}$ & 193 & $35,7 \%$ \\
\hline & & $\begin{array}{l}\text { Es un tema al que nunca le han } \\
\text { dado importancia }\end{array}$ & 26 & $4,8 \%$ \\
\hline \multirow{4}{*}{$\begin{array}{l}\text { Importancia del } \\
\text { cambio climático } \\
\text { entre los medios } \\
\text { de comunicación }\end{array}$} & \multirow{4}{*}{$\begin{array}{l}\text { 11. Desde su } \\
\text { percepción, ¿qué tanta } \\
\text { importancia le brindan los } \\
\text { medios de comunicación } \\
\text { al tema del cambio } \\
\text { climático? }\end{array}$} & $\begin{array}{l}\text { Es un tema al que le dan mucha } \\
\text { importancia }\end{array}$ & 56 & $10,4 \%$ \\
\hline & & $\begin{array}{l}\text { Es un tema al que dan algo de } \\
\text { importancia }\end{array}$ & 249 & $46,0 \%$ \\
\hline & & $\begin{array}{l}\text { Es un tema al que le dan poca } \\
\text { importancia }\end{array}$ & 211 & $39,0 \%$ \\
\hline & & $\begin{array}{l}\text { Es un tema al que nunca le han } \\
\text { dado importancia }\end{array}$ & 25 & $4,6 \%$ \\
\hline \multirow{4}{*}{$\begin{array}{l}\text { Importancia del } \\
\text { cambio climático } \\
\text { a nivel local - } \\
\text { departamental }\end{array}$} & \multirow{4}{*}{$\begin{array}{l}\text { 12. Desde su } \\
\text { percepción, ¿qué tanta } \\
\text { importancia le brinda } \\
\text { el gobierno local y } \\
\text { departamental al tema } \\
\text { del cambio climático? }\end{array}$} & $\begin{array}{l}\text { Es un tema al que le dan mucha } \\
\text { importancia }\end{array}$ & 22 & $4,1 \%$ \\
\hline & & $\begin{array}{l}\text { Es un tema al que dan algo de } \\
\text { importancia }\end{array}$ & 154 & $28,5 \%$ \\
\hline & & $\begin{array}{l}\text { Es un tema al que le dan poca } \\
\text { importancia }\end{array}$ & 299 & $55,3 \%$ \\
\hline & & $\begin{array}{l}\text { Es un tema al que nunca le han } \\
\text { dado importancia }\end{array}$ & 66 & $12,2 \%$ \\
\hline
\end{tabular}




\begin{tabular}{|c|c|c|c|c|c|}
\hline \multirow[t]{9}{*}{$\begin{array}{l}\text { Factores } \\
\text { asociados al } \\
\text { cambio climático }\end{array}$} & \multirow{9}{*}{$\begin{array}{l}\text { 13. En su opinión, } \\
\text { ¿cuáles son los } \\
\text { principales } \\
\text { de causa del cambio } \\
\text { climático? }\end{array}$} & \multirow{2}{*}{\multicolumn{2}{|c|}{$\begin{array}{l}\text { Las actividades productivas, por } \\
\text { ejemplo, ganadería, construcción, } \\
\text { minería. } \\
\text { El consumo humano }\end{array}$}} & 190 & $35,1 \%$ \\
\hline & & & & 165 & $30,5 \%$ \\
\hline & & \multicolumn{2}{|c|}{$\begin{array}{l}\text { El uso de energías basadas en } \\
\text { fuentes fósiles }\end{array}$} & 213 & $39,4 \%$ \\
\hline & & \multicolumn{2}{|c|}{$\begin{array}{l}\text { Las actividades de las empresas } \\
\text { en general }\end{array}$} & 135 & $25 \%$ \\
\hline & & \multicolumn{2}{|c|}{ La deforestación } & 389 & $71,9 \%$ \\
\hline & & \multicolumn{2}{|c|}{$\begin{array}{l}\text { El agotamiento de los recursos no } \\
\text { renovables }\end{array}$} & 221 & $40,9 \%$ \\
\hline & & \multicolumn{2}{|c|}{$\begin{array}{l}\text { La contaminación del aire y el } \\
\text { suelo }\end{array}$} & 414 & $76,5 \%$ \\
\hline & & \multirow[t]{2}{*}{ Otro } & La actividad del hombre & 1 & $0,2 \%$ \\
\hline & & & $\begin{array}{l}\text { Las malas prácticas de las } \\
\text { empresas }\end{array}$ & 1 & $0,2 \%$ \\
\hline \multirow{5}{*}{$\begin{array}{l}\text { Responsables } \\
\text { del cambio } \\
\text { climático }\end{array}$} & \multirow{5}{*}{$\begin{array}{l}\text { 14. En su opinión, } \\
\text { ¿cuáles son los } \\
\text { principales responsables } \\
\text { del cambio climático? }\end{array}$} & \multicolumn{2}{|c|}{ Las empresas } & 312 & $57,7 \%$ \\
\hline & & \multicolumn{2}{|c|}{ Los gobiernos - Estados } & 268 & $49,5 \%$ \\
\hline & & \multicolumn{2}{|c|}{ Las personas - sociedad } & 458 & $84,7 \%$ \\
\hline & & \multicolumn{2}{|c|}{ La naturaleza misma } & 58 & $10,7 \%$ \\
\hline & & Otro & $\begin{array}{l}\text { Empresas, seres humanos } \\
\text { y gobiernos }\end{array}$ & 10 & $1,8 \%$ \\
\hline \multirow[t]{8}{*}{$\begin{array}{l}\text { Efectos del } \\
\text { cambio climático }\end{array}$} & \multirow{8}{*}{$\begin{array}{l}\text { 15. En su opinión, } \\
\text { ¿cuáles son los } \\
\text { principales efectos del } \\
\text { cambio climático? }\end{array}$} & \multicolumn{2}{|c|}{$\begin{array}{l}\text { Destrucción de los ecosistemas y } \\
\text { agotamiento de recursos básicos } \\
\text { (p.e. el agua) }\end{array}$} & 460 & $85,0 \%$ \\
\hline & & \multicolumn{2}{|c|}{ Hambre y pobreza } & 67 & $12,4 \%$ \\
\hline & & \multicolumn{2}{|c|}{$\begin{array}{l}\text { El desplazamiento de poblaciones } \\
\text { o grupos humanos }\end{array}$} & 92 & $17,0 \%$ \\
\hline & & \multicolumn{2}{|c|}{ Los desastres naturales } & 371 & $68,6 \%$ \\
\hline & & \multicolumn{2}{|c|}{ El aumento del nivel del mar } & 122 & $22,6 \%$ \\
\hline & & \multicolumn{2}{|c|}{$\begin{array}{l}\text { Cambio de las condiciones } \\
\text { ambientales }\end{array}$} & 369 & $68,2 \%$ \\
\hline & & \multicolumn{2}{|c|}{ Deterioro de la salud humana } & 123 & $22,7 \%$ \\
\hline & & Otro & Contaminación & 1 & $0,2 \%$ \\
\hline \multirow{3}{*}{$\begin{array}{l}\text { Impactos del } \\
\text { cambio climático } \\
\text { sobre el mismo } \\
\text { individuo }\end{array}$} & 16. Desde & \multicolumn{2}{|c|}{ Sí, es lo más probable } & 380 & $70,2 \%$ \\
\hline & perspectiva, ¿considera & \multicolumn{2}{|c|}{ Sí, aunque es poco probable } & 111 & $20,5 \%$ \\
\hline & $\begin{array}{l}\text { que el cambio climático } \\
\text { tendrá un efecto o } \\
\text { impacto próximo sobre } \\
\text { usted? ¿Cuál? }\end{array}$ & \multicolumn{2}{|c|}{ No tendrá ningún impacto sobre mi } & 50 & $9,2 \%$ \\
\hline
\end{tabular}

Fuente: elaboración propia 
El $63,0 \%$ de los participantes interpretan el cambio climático como un fenómeno global que se caracteriza por la variación del clima. Otro $23,5 \%$ de estudiantes considera que este fenómeno se caracteriza por el deterioro de la capa de ozono y un $12 \%$ expresa que la característica esencial del cambio climático es el aumento de la temperatura. El $0,9 \%$ de los estudiantes agregaron a sus respuestas que el cambio climático va más allá de la variación del clima y compromete otros elementos geográficos.

El $53,6 \%$ de los universitarios afirma que las redes sociales son los medios más comunes por donde se encuentra información relacionada al cambio climático y el $44.7 \%$ considera que la televisión, la radio y los documentales transmitidos online o por televisión, corresponden a los espacios más comunes de información. Un $34,9 \%$ hace referencia a los foros, blogs y páginas web, y tan sólo el 23,5\% mencionan los informes y las revistas científicas. El $0,4 \%$ de los participantes hace mención a 'aplicaciones móviles'.

La $48,2 \%$ de los participantes considera que no hay relación alguna entre cambio climático y fenómenos como la pobreza, el hambre, el desempleo y la calidad de vida. Un $39,2 \%$ de universitarios cree que hay una relación indirecta entre estos y sólo el 12,6\% expresa que hay relaciones directas entre estos fenómenos.

Se indagó, además, por las conexiones establecidas entre el cambio climático y problemas cercanos a su realidad de nivel departamental, local o comunitario: el $53,4 \%$ de los participantes expresa que hay problemas en el territorio que tienen relación con el cambio climático, mientras que un $46,6 \%$ manifiesta no asociar problemas territoriales cercanos con el fenómeno del cambio climático. En el primer grupo, algunos problemas enunciados son: 'contaminación', 'aumento de las temperaturas o extremos calores', sequías', 'el daño sobre cultivos', 'el humo que estuvo presente varías semanas en toda la ciudad', 'la reducción del caudal de los ríos', 'la variación del aire', 'los escases de agua', 'deslizamientos en barrios periféricos de escasos recursos', 'derrumbes', 'temblores' y 'migraciones'.

También algunas preguntas se relacionaron con la percepción que tienen los estudiantes universitarios en torno a la importancia que se le da al tema del cambio climático desde distintas aristas. El $48,6 \%$ de los participantes indica que al tema le dan algo de importancia y el $38,4 \%$ describe que es un tema al que brindan mucha importancia. Estos resultados contrastan con la percepción de la importancia dada al cambio climático desde el Estado, los gobiernos locales, la sociedad y los medios de comunicación:

a. El $59,3 \%$ describe que el Estado y las organizaciones gubernamentales poca importancia le da al tema del cambio climático.

b. El $70,6 \%$ indica que la sociedad poca o ninguna importancia le da al fenómeno del cambio climático.

c. El $43,6 \%$ indica que los medios de comunicación poca o ninguna importancia le dan al fenómeno del cambio climático.

d. El $67,5 \%$ indica que el gobierno local / departamental poca o ninguna importancia le da al fenómeno del cambio climático.

e. El $40,2 \%$ indica que la universidad poca o ninguna importancia le da al fenómeno del cambio climático.

Para los universitarios, los principales factores de causa asociados al cambio climático son la contaminación del aire y el suelo $(76,5 \%)$, la deforestación $(71,9 \%)$, el agotamiento de los recursos renovables $(40,9 \%)$ y el uso de energía fósiles $(39,4 \%)$. También hay porcentajes algo 
significativos en otras opciones como las actividades productivas y el consumo humano. En cuanto a los principales responsables, la mayoría de universitarios destacan a las personas / sociedad $(84,7 \%)$, las empresas $(57,7 \%)$ y los gobiernos $(49,5 \%)$.

En relación con los efectos del cambio climático, estos se asocian con las siguientes imágenes: destrucción de ecosistemas y agotamientos de recursos básicos $(85,0 \%)$, desastres naturales $(68,6 \%)$ y cambio de condiciones ambientales (68,2\%). En menor grado se identifican el hambre, la pobreza, el desplazamiento de personas, el aumento del nivel del mar y el deterioro de la salud.

Para un $79,2 \%$ de los participantes, lo más probable es que exista un efecto próximo del cambio climático sobre sus propias vidas. Un $20,5 \%$ considera que habrá un efecto del cambio climático sobre sus vidas, aunque es poco probable. Sobre estas posibilidades, los universitarios identifican como algunos efectos próximos del cambio climático: 'salud', 'economía', 'fuentes hídricas' 'escases de recursos', 'deterioro de ecosistemas', 'inundaciones', 'deslizamientos' y 'disminución de la calidad del aire'.

Los hallazgos relacionados con la variable acciones frente al cambio climático, se describen en la tabla 4. La primera pregunta de esta sección se refirió a la actitud de los participantes frente al cambio climático: el $69,3 \%$ de los universitarios considera que su actitud frente al cambio climático es positiva, considerando que prestan atención cuando observan alguna información relacionada con el tema. Tan sólo un $21,6 \%$ de los jóvenes busca información para conocer sobre el tema.

Tabla 4. Resultados del cuestionario en torno acciones frente al cambio climático

\begin{tabular}{|c|c|c|c|c|}
\hline Dimensión & Ítem & Opciones & No & $\%$ \\
\hline \multirow[t]{5}{*}{ Actitudes } & \multirow{5}{*}{$\begin{array}{l}\text { 17. Frente al cambio } \\
\text { climático, usted puede decir } \\
\text { que su actitud ha sido: }\end{array}$} & $\begin{array}{l}\text { Positiva, por lo que busco } \\
\text { conocer sobre el tema }\end{array}$ & 117 & $21,6 \%$ \\
\hline & & $\begin{array}{l}\text { Positiva, por lo que muestro } \\
\text { interés cuando veo alguna } \\
\text { información }\end{array}$ & 375 & $69,3 \%$ \\
\hline & & $\begin{array}{l}\text { Negativa, por lo que me } \\
\text { resulta indiferente }\end{array}$ & 45 & $8,3 \%$ \\
\hline & & $\begin{array}{l}\text { Negativa, por lo que no creo } \\
\text { en el cambio climático }\end{array}$ & 1 & $0,2 \%$ \\
\hline & & Otra & 3 & $0,6 \%$ \\
\hline \multirow{6}{*}{$\begin{array}{l}\text { Consulta y } \\
\text { aprehensión de } \\
\text { conocimientos }\end{array}$} & \multirow{6}{*}{$\begin{array}{l}\text { 18. Para conocer más } \\
\text { sobre el tema del cambio } \\
\text { climático, procuraría: }\end{array}$} & $\begin{array}{l}\text { Consultar información en } \\
\text { línea }\end{array}$ & 354 & $65,4 \%$ \\
\hline & & Ver documentales & 312 & $57,7 \%$ \\
\hline & & $\begin{array}{l}\text { Asistir a conferencias o } \\
\text { talleres }\end{array}$ & 47 & $8,7 \%$ \\
\hline & & $\begin{array}{l}\text { Leer libros o artículos } \\
\text { científicos }\end{array}$ & 123 & $22,7 \%$ \\
\hline & & Ninguna de las anteriores & 35 & $6,5 \%$ \\
\hline & & Otro & 1 & $0,2 \%$ \\
\hline
\end{tabular}




\begin{tabular}{|c|c|c|c|c|}
\hline \multirow[t]{4}{*}{$\begin{array}{l}\text { Consumo de } \\
\text { energía }\end{array}$} & \multirow{4}{*}{$\begin{array}{l}\text { 19. Para ahorrar energía o } \\
\text { hacer un consumo adecuado } \\
\text { de la energía, procuro realizar } \\
\text { alguna estas tareas en casa u } \\
\text { otros lugares: }\end{array}$} & $\begin{array}{l}\text { Hacer una lectura crítica del } \\
\text { consumo de energía }\end{array}$ & 79 & $12,9 \%$ \\
\hline & & $\begin{array}{l}\text { Ahorrar el consumo de } \\
\text { energía }\end{array}$ & 457 & $84,5 \%$ \\
\hline & & $\begin{array}{l}\text { Invitar a los demás a realizar } \\
\text { acciones para el ahorro de } \\
\text { consumo de energía }\end{array}$ & 234 & $43,3 \%$ \\
\hline & & Ninguna de las anteriores & 26 & $4,8 \%$ \\
\hline \multirow{8}{*}{$\begin{array}{l}\text { Uso de fuentes } \\
\text { contaminantes }\end{array}$} & \multirow{8}{*}{$\begin{array}{l}20 . \quad \text { Para disminuir las } \\
\text { fuentes contaminantes, } \\
\text { procuro realizar alguna de } \\
\text { estas tareas en casa u otros } \\
\text { lugares: }\end{array}$} & Reciclar & 318 & $58,8 \%$ \\
\hline & & $\begin{array}{l}\text { Disminuir la generación de } \\
\text { basuras }\end{array}$ & 278 & $51,4 \%$ \\
\hline & & $\begin{array}{l}\text { Disminuir el uso de empaques } \\
\text { o bolsas de un solo uso }\end{array}$ & 327 & $60,4 \%$ \\
\hline & & $\begin{array}{l}\text { Usar bicicleta y no usar } \\
\text { medios de transporte que } \\
\text { utilizan fuentes fósiles de } \\
\text { energía }\end{array}$ & 113 & $20,9 \%$ \\
\hline & & $\begin{array}{l}\text { Utilizar en menor medida } \\
\text { fuentes contaminantes, p.e. } \\
\text { carbón }\end{array}$ & 177 & $32,7 \%$ \\
\hline & & $\begin{array}{l}\text { Utilizar en menor medida } \\
\text { electrodomésticos }\end{array}$ & 184 & $34,0 \%$ \\
\hline & & $\begin{array}{l}\text { Invitar a los demás al } \\
\text { desarrollo de prácticas para } \\
\text { disminuir las fuentes de } \\
\text { contaminación }\end{array}$ & 185 & $34,2 \%$ \\
\hline & & Ninguna de las anteriores & 19 & $3,5 \%$ \\
\hline \multirow[t]{5}{*}{$\begin{array}{l}\text { Consumo de } \\
\text { bienes }\end{array}$} & \multirow{5}{*}{$\begin{array}{l}\text { 21. Para disminuir el } \\
\text { consumo de bienes, procura } \\
\text { realizar alguna de estas tareas } \\
\text { en casa u otros lugares: }\end{array}$} & $\begin{array}{l}\text { Comprar bienes estrictamente } \\
\text { necesarios }\end{array}$ & 311 & $57,5 \%$ \\
\hline & & $\begin{array}{l}\text { Valorar los componentes de } \\
\text { los productos que compra }\end{array}$ & 187 & $34,6 \%$ \\
\hline & & $\begin{array}{l}\text { Valorar la responsabilidad } \\
\text { social de la empresa que } \\
\text { produce el bien que se oferta }\end{array}$ & 142 & $26,2 \%$ \\
\hline & & $\begin{array}{l}\text { Invitar a los demás para que } \\
\text { hagan un consumo racional } \\
\text { de productos }\end{array}$ & 203 & $37,5 \%$ \\
\hline & & Ninguna de las anteriores & 54 & $10 \%$ \\
\hline
\end{tabular}




\begin{tabular}{|c|c|c|c|c|c|}
\hline \multirow[t]{7}{*}{ Movilización social } & \multirow{7}{*}{$\begin{array}{l}\text { 22. Frente al problema del } \\
\text { cambio climático, se moviliza } \\
\text { socialmente a través de: }\end{array}$} & \multicolumn{2}{|c|}{ Protestas } & 79 & $14,6 \%$ \\
\hline & & \multicolumn{2}{|c|}{ Foros online } & 135 & $25 \%$ \\
\hline & & \multicolumn{2}{|c|}{ Firma de peticiones o cartas } & 166 & $30,7 \%$ \\
\hline & & \multicolumn{2}{|c|}{ Participación en vídeos } & 59 & $10,9 \%$ \\
\hline & & \multicolumn{2}{|c|}{$\begin{array}{l}\text { Publicaciones en redes } \\
\text { sociales }\end{array}$} & 292 & $54,0 \%$ \\
\hline & & \multicolumn{2}{|c|}{$\begin{array}{l}\text { Participaciones en grupos } \\
\text { ambientalistas }\end{array}$} & 111 & $20,5 \%$ \\
\hline & & \multicolumn{2}{|c|}{ Ninguna de las anteriores } & 117 & $21,6 \%$ \\
\hline \multirow[t]{5}{*}{$\begin{array}{l}\text { Estrategias y } \\
\text { proyectos propios }\end{array}$} & \multirow{5}{*}{$\begin{array}{l}\text { 23. Frente al problema } \\
\text { del cambio climático, ha } \\
\text { desarrollado alguna de estas } \\
\text { actividades: }\end{array}$} & \multicolumn{2}{|c|}{$\begin{array}{l}\text { Diseño de estrategias y } \\
\text { proyectos a nivel universitario }\end{array}$} & 61 & $11,3 \%$ \\
\hline & & \multicolumn{2}{|c|}{$\begin{array}{l}\text { Diseño de estrategias y } \\
\text { proyectos a nivel público o } \\
\text { comunitario }\end{array}$} & 62 & $11,5 \%$ \\
\hline & & \multicolumn{2}{|c|}{$\begin{array}{l}\text { Participación en estrategias o } \\
\text { proyectos de terceros como } \\
\text { organizaciones, grupos de } \\
\text { investigación u otros }\end{array}$} & 131 & $24,2 \%$ \\
\hline & & Otro & $\begin{array}{l}\text { Actividades y } \\
\text { semilleros en el } \\
\text { colegio }\end{array}$ & 3 & $0,6 \%$ \\
\hline & & \multicolumn{2}{|c|}{ Ninguna de las anteriores } & 333 & $61,6 \%$ \\
\hline
\end{tabular}

Fuente: elaboración propia

El $8,3 \%$ indica que su actitud es de indiferencia frente al cambio climático. Indica una estudiante: "no he podido crear hábitos, por el contrario, realizo acciones que tienen un impacto grave como el consumo de plástico en exceso, adicionalmente, no he trabajado en pro del ambiente, de hecho, pocas cosas que aporten a la causa". Otro estudiante observa que no es un tema que le ataña, sino que debe importar a los Estados, los cuales deben llegar a acuerdos globales que al incumplirse generen cierres comerciales: "[...] me da igual si al final se vuelve encima el planeta, pues morimos todos y ya está, [...] yo simplemente, no me mato la cabeza por eso e intento vivir mi vida de buena manera y lo que tenga que pasar".

Para conocer sobre el tema del cambio climático, los estudiantes utilizarían, principalmente, fuentes en línea $(65,4 \%)$ y documentales $(57,7 \%)$. Las acciones específicas en cuanto al consumo de energía, la principal estrategia es el ahorro de energía (84,5\%) e invitar a los demás a para el ahorro de energía $(43,3 \%)$. Las acciones para la reducción de fuentes contaminantes implementadas por lo sujetos son: reciclaje $(58,8 \%)$, disminución de empaques o bolsas de un solo uso $(60,4 \%)$ y disminución de basuras $(51,4 \%)$. Son pocos los que procuran no utilizar fuentes contaminantes como carbón o automóviles, electrodomésticos u optar por medios de transporte como la bicicleta.

En relación con el consumo de bienes, un $57,5 \%$ de los participantes manifestaron adquirir o comprar bienes estrictamente necesarios. Son pocos los que valoran la responsabilidad social de la empresa que produce el bien o los 
componentes del bien. Respecto de acciones de movilización social, la mayoría de los universitarios participa a través de publicaciones en redes sociales $(54,0 \%)$ o mediante la firma de peticiones o cartas $(30,7 \%)$. Por último, se indagó por la participación de los sujetos en estrategias y proyectos al interior de la universidad o fuera de ella: el $61,6 \%$ no realiza ninguna de estas actividades. Otros porcentajes inferiores de estudiantes indican que participan en proyectos universitarios, públicos, comunitarios o grupos de investigación, aunque estos son esporádicos.

Adicional al análisis descriptivo, se revisó la posible correlación entre las variables demográficas y las respuestas dadas por los participantes. En la tabla 5 se muestran estos hallazgos y se resaltan las correlaciones identificadas.

Tabla 5. Correlaciones entre variables socio-demográficas y preguntas

\begin{tabular}{|c|c|c|c|c|c|c|c|c|c|c|c|c|c|}
\hline \multirow[b]{2}{*}{$\begin{array}{l}\text { Variable } \\
\text { demográfica }\end{array}$} & \multicolumn{13}{|c|}{ Preguntas } \\
\hline & $\mathrm{P} 1$ & $\mathrm{P} 2$ & P3 & P5 & P6 & P7 & P8 & P9 & P10 & P11 & $\mathrm{P} 12$ & $\mathrm{P} 16$ & P17 \\
\hline Sexo & 0,070 & 0,011 & 0,100 & 0,422 & 0,385 & 0,567 & 0,024 & 0,491 & 0,218 & 0,772 & 0,811 & 0,946 & 0,015 \\
\hline Edad & 0,001 & 0,000 & 0,328 & 0,961 & 0,100 & 0,195 & 0,066 & 0,100 & 0,002 & 0,440 & 0,005 & 0,381 & 0,100 \\
\hline Estrato & 0,022 & 0,998 & 0,410 & 0,148 & 0,095 & 0,782 & 0,133 & 0,974 & 0,000 & 0,888 & 0,879 & 0,455 & 0,981 \\
\hline Programa & 0,197 & 0,219 & 0,126 & 0,000 & 0,391 & 0,764 & 0,090 & 0,144 & 0,272 & 0,253 & 0,235 & 0,045 & 0,576 \\
\hline Semestre & 0,165 & 0,678 & 0,135 & 0,776 & 0,424 & 0,580 & 0,663 & 0,158 & 0,020 & 0,245 & 0,627 & 0,840 & 0,418 \\
\hline Ubicación & 0,473 & 0,976 & 0,757 & 0,269 & 0,654 & 0,984 & 0,629 & 0,103 & 0,533 & 0,099 & 0,440 & 0,435 & 0,888 \\
\hline
\end{tabular}

Fuente: elaboración propia 
La variable sexo se correlaciona con las preguntas 2, 8 y 17: noción de cambio climático, percepción de la importancia que le da el Estado y las instituciones al cambio climático, y actitud que tienen los participantes al cambio climático. En general, las mujeres se inclinan a considerar el cambio climático como un fenómeno global caracterizado por la varianza del clima y brindar poca importancia al tema, aunque señalan que muestran interés sobre la información que les llega en relación a esta temática. En el caso de los hombres, no se marca tendencias significativas entre estos puntos consultados a través del instrumento y las respuestas tienden a dividirse de manera proporcional entre las diferentes opciones de respuesta.

La variable edad se correlaciona con las preguntas 1, 2, 10 y 12: percepción sobre el conocimiento que se tiene del cambio climático, noción sobre el cambio climático, percepción sobre la importancia que le da la universidad al tema y la importancia que le da el gobierno local al cambio climático. Los estudiantes sin importar su rango de edad señalan que conocen algo sobre el tema y se inclinan a considerar el cambio climático como un fenómeno caracterizado por el cambio del clima. Respecto a la importancia que le da la universidad al cambio climático, los estudiantes más jóvenes se inclinan a considerar que algo de importancia le da la universidad a este tema, mientras que los estudiantes entre 21 y 25 años consideran que es poca la importancia que se le brinda por parte de la universidad. Ahora bien, sin importar su edad, los participantes coinciden en señalar que es poca la importancia que le ha dado los gobiernos locales al tema del cambio climático.

La variable sociodemográfica estrato se correlaciona con las preguntas 1 y 10: percepción sobre el conocimiento que se tiene del cambio climático y percepción sobre la importancia que le da la universidad al tema. En el primer caso, sin importar el estrato al que pertenezcan los estudiantes, la tendencia es que conocen algo sobre el tema, y en el segundo, la inclinación es a opinar que la universidad poca importancia le da al fenómeno del cambio climático.

La variable programa académico se encuentra correlacionada con la pregunta 5 y 10: relaciones del cambio climático con fenómenos como la pobreza, el hambre, el desempleo y la calidad de vida; y percepción sobre la importancia que le da la universidad al tema. En el primer evento, se muestra que los estudiantes de administración de empresas y contaduría pública, se inclinan a señalar que no existe relaciones entre cambio climático y los problemas enunciados, mientras que la tendencia de los estudiantes de comercio internacional es considerar una relación indirecta entre estos fenómenos. En el segundo caso, los estudiantes de los programas administración de empresas y comercio internacional, se inclinan por señalar que la universidad le da algo de importancia al cambio climático, mientras que los estudiantes de contaduría pública consideran que es muy poca la importancia que se le brinda al tema.

\section{DISCUSIÓN}

Los hallazgos encontrados dentro de esta investigación, muestran que los jóvenes universitarios no tienen claridad sobre el fenómeno del cambio climático. Aunque todos los participantes afirman que no desconocen el término, en la mayoría de los casos se observan algunas ideas 0 imágenes fragmentadas asociadas al tema. Dada la urgencia y la crisis que implica el cambio climático, se esperaría que los sujetos en formación tuvieran una mayor claridad en torno al cambio climático, sus características, causas y efectos a corto y mediano plazo, y para este objetivo, la universidad juega un papel 
fundamental al ser catalizadora de búsqueda de soluciones y transformaciones sociales frente a los principales problemas glocales. En efecto, los resultados indican que la universidad escasa atención le brinda al fenómeno del cambio climático y que la información que tienen los universitarios ha sido adquirida en espacios extra académicos como sucede en el estudio de García et al. (2019).

Las percepciones y representaciones sociales en torno al cambio climático de los jóvenes universitarios, se relaciona, principalmente, con el calentamiento global, la contaminación y los desastres, y menos con conceptos claves como gases de efecto invernadero, derretimiento de los glaciares, fuentes de energía fósiles, productividad y consumo, y baja de temperaturas, que resultan más abarcadoras en la comprensión e interpretación del fenómeno del cambio climático. Estos hallazgos también se reflejan en otros estudios similares (Heras 2015; Santiago Horita y Sulvavarán 2018; Miranda et al. 2019).

Se destaca del conjunto de hallazgos como a los participantes universitarios, se les dificulta establecer relaciones entre el fenómeno del cambio climático y otros problemas estructurales. En efecto, para muchos no hay una relación directa entre la variabilidad climática y temas como el hambre, la pobreza o la calidad de vida, desconociendo situaciones provocadas por el cambio climático como es el caso de migraciones ambientales, una de estas ocurrida muy cerca de la ciudad de Cúcuta y que llevó al desplazamiento de más de 5 mil personas. Esta migración se prolongó por más de 5 años hasta que el Gobierno Nacional brindó una solución definitiva a estos desplazados ambientales a partir de la construcción de un nuevo casco urbano. Estos hechos, dejaron percepciones y representaciones colectivas bastante profundas sobre el cambio climático en los pobladores (Avendaño 2018). El ítem 6 de la tabla 3 informa que un porcentaje significativo de participantes no relaciona el cambio climático con situaciones y fenómenos que se han presentado en el departamento, el área metropolitana o en la misma ciudad de Cúcuta, y los cuales se encuentran conexos a la variabilidad climática.

Aunque para la mayoría de los participantes, la sociedad es el principal responsable del cambio climático, mensaje fuertemente socializado en distintos espacios tanto académico como informales, los estudiantes se valoran a sí mismos como sujetos que brindan especial importancia al tema de la variabilidad climática. A contrario sensu, perciben que es escasa la importancia dada al cambio climático por parte del Estado, entidades gubernamentales, gobiernos departamental y local, sociedad, medios de comunicación, e inclusive, la universidad. Sin embargo, las acciones de los jóvenes universitarios son escasas, transeccionales, no continuas, poco abarcadoras y no coherentes con los problemas locales. Esto se debe a que consideran que poco o nada se puede hacer desde un nivel preventivo, a fin de que el impacto del cambio climático pueda ser mitigado.

\section{CONCLUSIONES}

Los jóvenes universitarios tienen ideas, imágenes y conceptos fragmentados en torno al cambio climático. La información que han integrado a su saber, ha sido escasa y proviene, esencialmente, de espacios extra académicos. Esto incide en que las representaciones sociales sobre cambio climático resulten escasas, así como las relaciones y nexos con otros problemas glocales. Para muchos, el cambio climático no les afectará de manera próxima, pese a la evidencia del aumento de temperaturas, sequías, fuertes lluvias, inundaciones, deslizamientos, el agotamiento del recurso hídrico, entre otros.

Este desdén e indiferencia por el cambio climático, el cual se encuentra sujeto a la 
poca información interiorizada sobre el tema, lleva a la construcción de actitudes negativas caracterizadas por el rechazo del tema como punto central de interés en la vida cotidiana. De ahí que las decisiones y acciones de los sujetos, resulten pocas, insuficientes, poco abarcadoras y sin objetivos que medien el comportamiento de los individuos.

\section{REFERENCIAS}

Ambrogi, Rosario. 2016. "El cambio climático un problema económico". Revista Electrónica en Investigación en Ciencias Económicas, 4(8): 107-117. https://doi. org/10.5377/reice.v4i8.3059

Avendaño, William. 2018. "El territorio como recurso de uso común para el caso del municipio de Gramalote, Norte de Santander", Disertación doctoral, Pontifica Universidad Javeriana.

Avendaño, William, Carlos Patiño y Daniel Aguilar. 2017. "New approaches to planning and development: the case of Gramalote, Norte de Santander, Colombia". Cuadernos de Administración, 33(58): 77-89. http:// dx.doi.org/10.25100/cdea.v33i58.4704

Avendaño, William y Daniel Aguilar. 2014. "Geopolítica y medio ambiente: una Mirada a la problemática de los desplazados ambientales". Investigación \& Desarrollo, 22(2):283308.

Ballesteros, Henry y Gloria León. 2007. Información sobre gases de efecto invernadero y el cambio climático. Bogotá: Instituto de Hidrología, Meteorología y Estudios Ambientales IDEAM.

Batel, Susana, Paula Castro, Patrick Devine y Caroline Howarth. 2016. "Developing a critical agenda to understand proenvironmental actions: contributions from Social Representations and Social Practices Theories". WIREs Climate Change, 7(5): 727-745. https://doi. org/10.1002/wcc. 417

Congreso de la República. 2018, 27 de julio. Ley 1931. Diario Oficial No. 50.667, del 27 de julio de 2018.

Congreso de la República. 2019. Proyecto de Ley 208/2019 Cámara 'Por medio de la cual se fijan parámetros para otorgar beneficios e incentivos para el fomento e implementación de Construcción Sostenible y se dictan otras disposiciones'.

Departamento Nacional de Planeación -DNP-. 2018. Plan Nacional de Adaptación al Cambio Climático. Bogotá: DNP.

Domínguez, Fernando. 2001. "Teoría de las representaciones sociales. Apuntes". Nómadas, (3): 1-15.

Flores, Raúl. 2019. "Las representaciones sociales sobre el cambio climático de los estudiantes de pedagogía en México: un acercamiento desde la perspectiva de género". Educación, 28(54): 7-26. https://doi.org/10.18800/ educacion.201901.001

Flores, Raúl y Esperanza Terrón. 2018. "Las emociones en las representaciones sociales del cambio climático. Educar em Revista, 34(68): 217-233. https://doi. org/10.1590/0104-4060.55684 
Forero, Germán, Juan Pablo Saldarriaga y Melissa Vargas. 2017. "Cambio climático: impactos y perspectivas de investigación desde una visión multidisciplinar". Tendencias, 18(2): 122-138. http://dx.doi.org/10.22267/ rtend. 171802.80

García, Antonio, Pablo Meira, Mónica Blanco y Kylyan Bisquert. 2019. "Social representations of climate change in a group of college students from the University of Santiago de Compostela: common culture vs. scientific culture". Eco-Thinking, 1: 1-18.

García, Nicasio, Rocío Vargas y Casimiro Leco. 2010. "Imaginarios, Percepciones y Representaciones Sociales de la Migración Internacional: Un acercamiento teórico-metodológico para su estudio en el ámbito comunitario". CIMEXUS, 5(1): 59-69.

Harvey, Danny. 2000. Climate and global environmental change. New York: Routledge.

Heras, Francisco. 2015. "Representaciones sociales del cambio climático en España: aportes para la comunicación", disertación doctoral, Universidad Autónoma de Madrid.

Jodelet, Denise. 1986. "La representación social: fenómenos, concepto y teoría”. En Psicología Social. Vol.2: Pensamiento y vida social. Psicología social y problemas sociales, dirección de Serge Moscovici, 469-495. Barcelona: Paidós.

Kellogg, William. 2019. "Human impact on climate: the evolution of an awareness". En Societal responses to regional climatic change. Forecasting by analogy, editado por Michael Glantz, 113-136. New York: Routledge.
Kellogg, William y Robert Schware. 2018. Climate change and society. Consequences of increasing atmospheric carbon dioxide. New York: Routledge.

Ministerio de Ambiente y Desarrollo Sostenible. 2017. Política Nacional de Cambio Climático (Ministerio de Ambiente y Desarrollo Sostenible. Bogotá: Ministerio de Ambiente y Desarrollo Sostenible.

Miranda, Clara, Marileny Ramos, Regla Alomá y María Castellanos. 2019. "Percepción social del cambio climático. Estudio en comunidades costeras de la provincia de Cienfuegos Social". Revista Cubana de Meteorología, 25: 334-353.

Moloney, Gail, Zoe Leviston, Timothy Lynam, Jennifer Price, Samantha Stone y Duncan Blair. 2014. "Using social representations theory to make sense of climate change: what scientists and nonscientists in Australia think". Ecology and Society, 19(3): 9-18. http://dx.doi. org/10.5751/ES-06592-190319

Moscovici, Serge. 1979. El psicoánalisis, su imagen y su público. Buenos Aires: Huemel.

Moscovici, Serge. 1998. "The history and actuality of social representations". En The psichology of the social, editado por Uwe Flick, 209-247. Cambridge: Cambridge University.

Naciones Unidas. 2007. Climatic change: impacts, vulnerabilities and adaptation in developing countries. Bonn: UNFCCC. 
Nawrotzki, Raphael, Lori Hunter, Daniel Runfola y Fernando Riosmena. (2015). "Climate change as a migration driver from rural and urban Mexico". Environmental Research Letters, 10(11): 1-9. http://dx.doi.org/10.1088/17489326/10/11/114023

Parra, Elizabeth, Claudia Castillo y Miriam Vallejos. 2013. "Representaciones sociales sobre desarrollo sostenible y cambio climático en estudiantes universitarios". Perspectivas de la Comunicación, 6(1): 108-119.

Pickel, Andreas. 2016. "El problema del cambio climático en perspectiva sistémica". Cultura y Representaciones Sociales, 11(21): 29-54. http://www.scielo. org. $\mathrm{mx} / \mathrm{pdf} / \mathrm{crs} / \mathrm{v} 11 \mathrm{n} 21 / 2007-8110$ crs-11-21-00029.pdf

Riosmena, Fernando, Raphael Nawrotzki y Lori Hunter. 2018. "Climate migration at the height and end of the Great Mexican Emigration Era". Population and Development Review, 44(3): 455-488. http://dx.doi.org/10.1111/padr.12158

Sánchez, Norma, Guadalupe de la Lanza, Rene Garduño, Rubén Sánchez. 2015. "La influencia antropogénica en el Cambio Climático bajo la óptica de los Sistemas Complejos". Revista Iberoamericana de Ciencias, 2(6):69-84. http://www.reibci. org/publicados/2015/nov/1300106.pdf

Santiago, José, Luz Horita y José Sulvarán. 2018. "El cambio climático y sus representaciones sociales en el medio rural de Chiapas, México". Ambiente y Desarrollo, 22(42): 1-12. https://doi. org/10.11144/Javeriana. ayd22-42. $\underline{\mathrm{ccrs}}$
Sivaramanan, Sivakumaran. 2016. Global Warming: Global Warming and Climate change causes, impacts and mitigation. Battaramulla: Central Environmental Authority CEA.

Teso, María. 2017. "Comunicación y representaciones del cambio climático: el discurso televisivo y el imaginario de los jóvenes españoles", disertación doctoral, Universidad Complutense de Madrid.

Ulloa, Astrid. 2011. "Construcciones culturales sobre el clima". En Perspectiva culturales del clima, editado por Astris Ulloa, 33-54. Bogotá: ILSA; Universidad Nacional de Colombia.

Wibeck, Victoria. 2014. "Social representations of climate change in Swedish lay focus groups: Local or distant, gradual or catastrophic?". Public Understanding of Science, 23(2): 204-219. https://doi. org/10.1177/0963662512462787 